\title{
¿Qué es la ética de la empresa?
}

David Sobrevilla Alcázar

Es profesor de las facultades de Ingeniería Industrial y de Derecho y Ciencias Políticas de la Universidad de Lima. Ha sido profesor de las universidades Nacional Mayor de San Marcos y Cayetano Heredia y profesor visitante de las universidades de Wisconsin (Madison, EE UU) y de California (Davis, EE UU), y de la Universidad de Carabobo (Venezuela). Ha publicado una decena de libros y editado otros tantos. Su última obra se titula Repensando la tradición de nuestra América. Estudios sobre la filosofía en América Latina.

En este artículo pretendemos ofrecer una idea de la ética de la empresa y de algunos de los principales problemas que plantea. En la primera parte nos referiremos a la ética en general, y en la segunda, que se publicará en el siguiente número, trataremos parte de la temática de la ética empresarial. En una presentación más extensa tendríamos que ampliar nuestra exposición y tratar otros problemas a los que aquí, por falta de espacio, no nos podemos referir. 


\section{1. Ética y moral}

En el lenguaje coloquial ética y moral son palabras que se emplean de manera intercambiable, lo que se explica porque la segunda se remite a la traducción ciceroniana de la hethiké griega como philosophia moralis (filosofía moral). Ethos fue en griego primero residencia, morada o lugar donde se habita, $\mathrm{y}$ luego costumbre, modo de ser y carácter.

Pero con la evolución filosófica se ha tendido a diferenciar entre ambos vocablos. Así, Hegel distinguía entre la moralidad como el comportamiento moral subjetivo y la eticidad como la moralidad objetiva. El día se hoy se tiende a separar más bien entre lo moral como el comportamiento individual o colectivo orientado hacia los valores, en especial hacia los del bien y el mal; y la ética como la disciplina filosófica práctica que estudia dichos comportamientos.

\section{2. Ética prefilosófica, ética religiosa, ética cotidiana y ética filosófica}

En verdad, en todas las culturas ha existido y existe una visión preteorética y prefilosófica de lo moral. Así, por ejemplo, en la Odisea se le dice a Odiseo que debe regresar pronto a Itaca si no quiere que le pase lo mismo que le ocurrió a Agamenón al volver a Troya; y entre los antiguos peruanos se manifiesta que existían las máximas "no robes, no mientas y no seas ocioso"1. Por su lado, entre los kpelle (en Liberia) existe la máxima que se aplica sobre todo a las relaciones entre los esposos: "Queremos dormir bien y no odiar a nuestros compañeros"2.

Antes de que surgiera la filosofía en Grecia, la ética era en casi todas las culturas parte de la religión, siendo fundamentada, por lo tanto, por el dogma religioso. Podemos, en este sentido, encontrar una ética judía, islámica, hinduista, china (en el confucionismo, en el taoísmo, etc.) y en otras religiones -empleando la palabra religión en sentido amplio, de modo de incluir todas estas distintas variedades de creencia. En el budis-

1 Marzal, M. La transformación religiosa peruana. Lima: PUC, 1983, p. 433 aunque hay quienes sostienen que estas máximas en realidad proceden de los españoles.

2 Dupré, W. Ethik in nichtchristlichen Kulturen. Stuttgart: Kohlhammer, 1984, p. 187. 
mo, Buda recomienda por ejemplo: "Abstente de causar daño a un ser vivo", en aplicación de la ley del karma, o sea del principio de que todas las acciones ocurren conforme a leyes causales y que, puesto que toda la realidad es una sola, aquello que yo haga a cualquier aspecto de la realidad me lo hago a mí mismo ${ }^{3}$. En la moral predicada por Jesús el amor es el mandato más importante que se extiende incluso a los enemigos: "Amad a vuestros enemigos, haced el bien a los que os odian, bendecid a los que os maldicen, rezad por los que os injurian"4.

Pero ni siquiera es preciso ir tan lejos; aun en la vida cotidiana existen máximas morales ampliamente conocidas como la famosa regla de oro: "Obra con los demás del mismo modo como los demás quieres que obren contigo"; o la así llamada regla de plata: "No hagas a otro lo que no quieres que te hagan a ti". En verdad, las personas casi siempre saben lo que deben hacer, aunque no lo sepan con claridad o no lo puedan fundamentar.

Las éticas filosóficas se distinguen de las prefilosóficas, porque son éticas que surgen habitualmente después de que se ha problematizado la ética religiosa tradicional o la cotidiana (que son dos cosas distintas). Por ello mismo, son éticas que se busca fundamentarlas en verdades teóricas y no en la tradición y/o en el dogma. Y que se caracterizan además porque sus máximas son más generales que las de la ética de la vida cotidiana.

En el proceso de la secularización de la vida, que es condición indispensable para el surgimiento de las éticas filosóficas en Grecia y en el Occidente, podemos distinguir dos momentos básicos: la problematización de la religión olímpica griega y de las demás corrientes religiosas existentes en la Hélade, proceso que tuvo lugar desde el siglo VII en adelante, y el cuestionamiento de lo religioso por la Ilustración en el siglo XVIII en Europa.

Quisiéramos indicar expresamente que el proceso del paso de las éticas tradicionales y religiosas a las filosóficas no significa, necesariamente y en todas partes, un progreso.

3 Bush Mitchell, V.E. Raíces de la sabiduría. México: International Thompson, 1998; II, p. 481 .

4 Lucas 6: 27-28; Cf. Mateo 5: 38-48, según José Gómez Cafarena, "El cristianismo y la filosofía cristiana", en Camps, V. (ed.). Historia de la ética. Barcelona: Crítica, 1988, I, 


\section{Algunas de las grandes orientaciones de la ética filosófica}

\subsection{La ética de la Antigüedad y de la Edad Media}

La ética de la Antigüedad y de la Edad Media se formula básicamente las siguientes preguntas: ¿en qué consiste el vivir bien? y icómo deben comportarse los seres humanos (R. Popkin y A. Stroll).

\subsubsection{Aristóteles}

Aristóteles nació en el 384 o 383 a.C. en Estagira (razón por la que se le llama Estagirita) y falleció en Calcis el año 322 a.C. Ha escrito tres grandes libros sobre ética: la Magna moral, la Ética a Eudemo y la Ética a Nicómaco. Nosotros sólo nos ocuparemos aquí de esta última.

Aristóteles comienza estableciendo que en nuestra vida existen fines mediatos, que queremos para alcanzar otros fines, y fines finales, que queremos por ellos mismos. Al fin final al que aspiramos lo llamamos bien, y el autor sostiene que existe un acuerdo casi unánime "entre la mayoría y los espíritus selectos" sobre que al fin más excelso de la vida humana se le llama felicidad. Pero luego de este acuerdo sobre el nombre hay un desacuerdo sobre la cosa que designa. En efecto, hay quienes hacen consistir la felicidad en el placer, otros en la riqueza, unos terceros en el honor y otros en muchas cosas más.

A continuación Aristóteles va a descartar muchas de estas respuestas: la felicidad no puede consistir en una vida placentera, porque ella nos hace "semejantes a los esclavos" y llevar una "existencia digna de las bestias". Tampoco puede residir la felicidad en una vida consagrada a la riqueza, ya que ésta no es un fin final sino sólo mediato: la riqueza sólo es un medio para obtener otros bienes, salvo el caso extremo del avaro. La felicidad tampoco puede consistir en una vida dedicada a los honores, pues éstos dependen más de quienes los conceden que de quienes los reciben, y nosotros consideramos que el bien es algo individual e inalienable. Tampoco podríamos situar el bien en una instancia trascendente -como quería Platón-, pues el bien debe ser para el ser humano algo realizable y actuable en este mundo.

¿En qué consiste entonces la felicidad para Aristóteles? Su respuesta tiene que ver con su concepción del ser humano y de 
la realidad. Según el Estagirita distinguimos en el ser humano entre una vida vegetativa, otra sensitiva $y$, finalmente, una intelectual. La felicidad del hombre sólo podrá consistir en la actividad de la parte humana superior, esto es la actividad del alma -y no la del cuerpo- según su perfección máxima o virtud. De ahí que la definición que ofrece el autor del bien supremo del hombre (es decir, la felicidad) sea "la actividad del alma según la virtud; y si son múltiples las virtudes según la mejor y más perfecta", donde hay que entender por virtud la excelencia alcanzada por algo. Conforme a esta definición la felicidad no se posee de una vez y para siempre sino que es una actividad que se lleva a cabo: una manera de desarrollar las posibilidades del alma a las que hay que desplegar virtuosamente, esto es, en la mejor forma posible. La felicidad es, pues, la actividad del alma según la virtud.

¿Y qué es la virtud moral? Hablamos de virtudes morales en el caso de actos voluntarios y racionales. Las virtudes son hábitos de comportamiento, la capacidad de dominar nuestros deseos, emociones y temores, que procede de nuestra parte racional y que puede ser desarrollada por medio del ejercicio hasta lograr su plena posesión, a fin de adecuar nuestra conducta a un canon de comportamiento impuesto por la tradición ${ }^{5}$. La razón interviene en este caso como razón práctica, frónesis o prudencia, que nos permite elegir siempre el justo medio entre dos comportamientos extremos (por exceso y por defecto); así, por ejemplo, la frónesis nos lleva a elegir el comportamiento valiente entre la temeridad y la cobardía; el comportamiento temperado entre el libertinaje y la sensibilidad, y el comportamiento liberal entre la prodigalidad y la avaricia. En consecuencia, en la vida práctica el hombre debería comportarse guiado por las virtudes o los hábitos de comportamiento que le permiten escoger, gracias a la prudencia, el justo medio entre dos conductas extremas.

Pero como hay grados entre las virtudes es más razonable pensar que la felicidad más cumplida será aquélla que se realice según la virtud más alta del hombre. Ésta es para Aristóteles la actividad contemplativa, que en cierta forma nos pone en

5 Guariglia, V.O. La ética en Aristóteles o la moral de la virtud. Buenos Aires: Eudeba, 1997, pp. 196 y 294. 
contacto con la vida divina, ya que lo propio de Dios es la contemplación. Mas para poder llevarla a cabo será necesario que contemos con ciertos bienes de fortuna y que el acto de contemplación no sea único ni esporádico sino en una vida completa: "Pues así como una golondrina no hace primavera, ni tampoco un día de sol, de la propia suerte ni un día ni un cierto tiempo hacen a nadie bienaventurado y feliz". Una vida dedicada a la contemplación, con ciertos bienes de fortuna y a lo largo de toda nuestra existencia es, pues, la vida plena de dicha o felicidad.

Quisiéramos agregar algunos puntos de crítica a la doctrina ética aristotélica. Uno es que parece existir una cierta incongruencia entre sus propuestas: por un lado, la felicidad es concebida como la vida virtuosa, y por otro, como la vida consagrada a la contemplación, concepciones ambas que se encontrarían en la Ética Nicomaquea confundidas y entremezcladas (W.F.R. Hardie). Otra es la objeción kantiana de que la felicidad no puede ser el fin último de la vida humana, porque se trata de algo egoísta. Y, por último, con relación a las virtudes morales, no siempre se puede encontrar un justo medio frente a ellas: ¿cuál sería, por ejemplo, el justo medio entre cumplir una promesa y no cumplirla, entre decir la verdad y no decirla?

\subsubsection{El epicureísmo o hedonismo}

El epicureísmo o hedonismo fue fundado por Epicuro, quien debe haber nacido en Samos a comienzos del 341 a.C. y fallecido el 270. Parece que escribió mucho, 37 libros, pero sólo han llegado a nosotros algunas cartas, el texto Pensamientos capitales, y fragmentos.

Para Epicuro el placer es el bien primario e innato y el fin de la vida feliz. De él derivamos toda elección o rechazo y llegamos a él valorizando todo bien con el criterio del efecto que produce. Pero en contra de lo que se pueda pensar, Epicuro no recomendaba una vida disipada y de excesos sino que, por el contrario, observaba que hay que distinguir entre aquellos placeres que no traen aparejado ningún sufrimiento y los que van acompañados por él, y que por ello debemos elegir los primeros. A aquéllos los denominamos placeres pasivos, por ejemplo la amistad, y a éstos placeres dinámicos, como la glotonería o sexualidad.

De allí que haya que realizar un cálculo y medida de los placeres y sobre todo de los deseos. Frente a todo deseo siempre 
hay que preguntarse: ¿qué me acontecerá si lo cumplo? Hay deseos que son naturales y necesarios; otros naturales pero no necesarios; y unos terceros que no son ni naturales ni necesarios, sino que son nacidos de una opinión vana. Deseos innaturales son los artificiales, e innecesarios son aquéllos que causan dolor si son satisfechos y que pueden ser fácilmente rechazados.

La norma de la conducta es según Epicuro obeceder a la naturaleza y bastarse a sí mismo. Si así procedemos, nos contentaremos con poco, íntimamente persuadidos de que gozan más quienes menos necesidad tienen; que es fácil lo que la naturaleza quiere y difícil lo que es vano. Y su ideal de vida era una existencia serena, sin angustiarse por lo que no se tiene, y satisfecho por lo que ya se posee, pues "Quien menos siente la necesidad del mañana, más alegremente se prepara para el mañana". En cambio, la vida del insensato está dirigida siempre hacia el futuro y está penetrada por una trepidación constante. En lugar de comportarnos así, el recuerdo de las cosas de que hemos gozado debería consolarnos de los males presentes que pudiéramos padecer.

Richard Popkin y A. Stroll han distinguido entre un hedonismo psicológico y otro ético: el primero afirma que de hecho la gente persigue el placer y sólo el placer en sus vidas, y que, por lo tanto, toda su actividad está dirigida a adquirir el placer y a evitar el dolor. Y de otro lado, el hedonismo ético sostiene que no sólo de hecho la gente busca el placer, sino que lo debe hacer, ya que para ella sólo el placer es el bien. Epicuro habría sido un hedonista tanto psicológico como ético. Según estos autores no son defendibles ni el hedonismo psicológico ni el ético. El primero, porque podemos comprobar en la vida diaria que mucha gente posterga la satisfacción de los placeres que pudiera experimentar en aras de obtener riquezas, poder $\mathrm{u}$ otros bienes; o que se sacrifica a sí misma por ciertos valores en los que creen. El hedonismo ético sostiene -como dijimos- que la buena vida es la vida de los placeres y que la gente debería tener como motivación de sus acciones la adquisición del placer. Pero ya Aristóteles había sostenido que algunos placeres podrían ser dañinos y que, por lo tanto, no puede considerarse la vida de placeres como la vida buena. Por otro lado, aun un placer como el producido por la amistad trae a veces sufrimientos. Finalmente, aunque la búsqueda del placer sea una motivación muy importante de la gente, sería difícil sostener que es la motivación más importante para sus actos; y, en todo caso, una socie- 
dad donde la gente actuara sólo buscando el placer desembocaría seguramente en un $\operatorname{caos}^{6}$.

\subsubsection{El estoicismo}

El estoicismo fue fundado por Zenón de Citio (336-264 a.C.) y ha tenido una evolución muy amplia que se extiende de la época griega a la romana. El estoicismo antiguo surgió en el siglo III a.C. y tuvo tres grandes cultivadores: el mismo Zenón, Cleantes y Crisipo. El estoicismo medio se desarrolló en el siglo II a.C. y fueron sus representantes Diógenes de Babilonia, Antípater de Tarsos y Posidonio de Apamea. El estoicismo imperial se produjo en los siglos I y II d.C., habiendo sido sus principales figuras sobre todo filósofos romanos: Séneca, Musonio Rufo, Epicteto y Marco Aurelio.

El estoicismo estuvo dominado por la vivencia de la decadencia de su época y de las costumbres, y de allí que haya propuesto como ideal el del sabio que ha extirpado sus pasiones (apatia), que cultiva la imperturbabilidad (ataraxia), no se admira de nada (nihil mirari) y que es ciudadano no de una ciudad (polites) sino del mundo (cosmopolites).

El estoicismo sostenía que el impulso primordial en los animales es la conservación de su propio ser, impulso que los lleva a rechazar lo que les es perjudicial y a buscar lo que les es útil. El placer sería sólo un fenómeno agregado que se produce cuando la naturaleza obtiene las condiciones convenientes a su propia constitución. De allí que los seres vivos puedan distinguir desde que nacen lo que concuerda con $s u$ propia naturaleza, y que se pueda decir que vivir de acuerdo con ella sea vivir de acuerdo con la naturaleza. Mas habiendo recibido los seres humanos la razón deben conducirse según ella, pues ésta orienta sus impulsos, no siendo en verdad nada distinto a la naturaleza. En consecuencia, vivir conforme a la razón es vivir conforme a la naturaleza. Es a través de la razón que el hombre supera a los animales e imita a los dioses, siendo por lo tanto la perfecta razón el supremo bien del hombre.

6 Popkin, R. y A. Stroll. Philosophy made simple. Nueva York: Doubleday, 1993, pp. 12 15. 
El fin supremo del hombre, el supremo bien, es por lo tanto vivir de acuerdo con la naturaleza en la que se encuentra la razón. Una vida semejante es una vida armoniosa y feliz. Y es además una vida útil, entendiendo esta palabra no en el sentido del utilitarismo posterior sino en el del entender el sentido del Destino o de la voluntad de Dios. Este naturalismo nos permite clasificar las cosas existentes: unos son bienes como la reflexión, la justicia, el coraje, la sabiduría; otros son males como la ausencia de reflexión, la injusticia, la cobardía, la ignorancia; y otros no son ni bienes ni males sino cosas indiferentes, porque no son ni útiles ni nocivas, como la vida, la muerte, la salud, la enfermedad, el placer, etc. Son indiferentes, porque ni nos sirven ni son dañinas, aunque el hombre pueda servirse de ellas para dañar o ser útil.

Conforme a lo dicho, la virtud consiste en vivir de acuerdo con la naturaleza, por lo que hay que abstenerse de todo lo que prohíbe la ley común. De allí que deba seguirse escrupulosamente el destino y que haya que sometérsele aun a costa del sacrificio de la propia vida.

Voluntad es desear algo con razón, mientras que excitarse con mucha vehemencia y en contra de la razón es someterse a la lujuria o concupiscencia desenfrenada. Las pasiones son las conmociones del alma opuestas a la razón. Por ello tienen que ser extirpadas del alma, al igual que los deseos que turban al ser humano, buscando lograr tener un ánimo tranquilo, en armonía consigo mismo, sin molestias, temores ni codicia.

Sabio es quien vive de acuerdo con la naturaleza y conforme a la razón. Quien está exento de pasiones y no es afectado por el sufrimiento, por lo que es libre. El sabio limita sus deseos a lo que de él depende y permanece enhiesto en medio de los peores males, porque sabe que no podrá ser tocado interiormente. Ni siquiera la muerte lo angustia, pues ella no es más que una operación de la naturaleza. Y sabio es asimismo quien no procede de una ciudad determinada sino del amplio mundo, cuyas leyes son las mismas por doquier.

Entre las críticas que se han dirigido contra el estoicismo se encuentra la problematización de que exista un núcleo racional a la base de la naturaleza y de la historia, de que exista una predestinación como el estoicismo pretende, el hecho de que este movimiento esté condicionado por la época de crisis en la que apareció y el quietismo y la pasividad a los que puede conducir. 


\subsubsection{Tomás de Aquino}

Tomaremos como una de las principales orientaciones del pensar cristiano en cuanto a la ética, la que se puede encontrar en las obras de Tomás de Aquino.

Tomás de Aquino nació en 1224 o 1225 en Rosasecca y falleció el año 1274. Este autor buscaba conciliar ideas griegas -sobre todo las de Aristóteles- con la verdad revelada por la religión cristiana. En su opinión, todo agente obra en razón de un fin; así también el hombre que -a diferencia de los otros seres- obra en forma voluntaria y racional. El fin último del hombre, su sumo bien, es Dios. Cuando el hombre lo alcanza logra la felicidad, algo que no es posible en este mundo sino sólo en la vida eterna. En este sentido, ni las riquezas, ni los honores, ni el poder ni el placer pueden colmar de felicidad al hombre, sino sólo Dios.

La vida apropiada para lograr la felicidad es la vida virtuosa. Las virtudes son hábitos para hacer el bien. En tanto distinguimos en el hombre su comportamiento moral, su capacidad de intelección y su destino espiritual, diferenciamos entre tres grupos de virtudes: morales, intelectuales y teologales. Los hábitos morales son la templanza (que tiene que ver con el dominio de lo concupiscible), la fortaleza (que regula lo irascible), la prudencia (que es la moderación racional) y la justicia (que tiene que ver con la relación entre las partes y el todo). Las virtudes intelectuales son la inteligencia, la ciencia y la sabiduría. Y, finalmente, las virtudes teologales son específicamente cristianas y son la fe, la esperanza y la caridad, que son virtudes sobrenaturales -en cambio las morales e intelectuales se remiten a las virtudes naturales de Aristóteles-.

Tomás de Aquino completa este cuadro con lo relativo a la moral social, a propósito de lo que extiende sus consideraciones sobre la justicia, y con un examen muy detallado de los vicios y pecados o sea de los hábitos y actos desordenados. Para él es vicioso todo lo que se hace fuera de la recta razón, la que quiere que se haga uso de los medios en la medida requerida para su fin. En este sentido, la embriaguez es un acto inmoderado y es un pecado, así como los excesos sexuales; en cambio, la abstinencia con respecto a las bebidas y la castidad con relación a los placeres sexuales pueden ser cosas eminentemente loables, ya que mantienen al hombre en un estado favorable a la forma de vida más alta que le es accesible. 
La ética cristiana ha sido objetada por diversas razones. Una de ellas es que presupone el creer en el dogma cristiano. Otra es la objeción kantiana en el sentido de que no es muy moral creer en los mandamientos de un Dios externo a nosotros que nos impone heterónomamente su voluntad a cambio de ciertas recompensas, objeción que no alcanzaría por cierto la ética del Sermón de la Montaña en que se prescinde de ofrecerlas. Y una tercera objeción es la nietzscheana en el sentido de que la ética cristiana sólo sería una interpretación de la ética griega, que traicionaría su propia experiencia original y además la helénica.

\subsection{La ética de la Época Moderna y de la Contemporánea}

Por razones que no son del caso aclarar aquí la ética moderna ya no formula las mismas preguntas que la ética de la Antigüedad sino más bien ésta: ¿qué debo hacer para actuar correctamente? (A. MacIntyre). Finalmente, la ética contemporánea se ha dedicado de preferencia, aunque no exclusivamente, a analizar el significado emotivo o conceptual de los términos que componen el lenguaje moral -términos como "bueno", "malo", “correcto", "incorrecto", etc.

\subsubsection{Kant}

Inmanuel Kant nació en Koenisberg en 1724 y falleció en la misma ciudad en 1804. Entre sus obras dedicadas a la filosofía moral se encuentran: Fundamentación de la metafísica de las costumbres (1785), Crítica de la razón práctica (1788) y Metafísica de las costumbres (1797). Según Kant, lo único incondicionalmente bueno en el mundo es la buena voluntad, es decir, la voluntad con independencia de su fin y de la consecución de sus propósitos. Que esto es así se observa en que el hombre está dotado de razón con el fin de producir una buena voluntad. En cambio, si la finalidad del hombre fuera su conservación, su bienestar o su felicidad, hubiera sido mejor que la naturaleza lo hubiera dotado del instinto, que es un medio mucho más adecuado para conseguir aquellos objetivos. La buena voluntad no está en relación con una meta particular determinada, sino con el concepto del deber u obligación: se obra bien cuando se actúa por deber, es decir, no meramente de acuerdo con él sino cuando el móvil de la acción es el deber. El deber es la necesidad de 
una acción por respeto a la ley. El respeto es un sentimiento producido por un concepto racional, es decir que no es el resultado de una inclinación ni es provocado por un objeto exterior, sino una resonancia de la ley que procede de nosotros mismos. El deber es la ética en forma del imperativo que nos imponemos a nosotros mismos en forma categórica. El imperativo categórico tiene distintas formulaciones. Una de las más conocidas es la siguiente: "Obra de tal modo que la máxima de tu acción se convierta en ley universal". Otra es: "Obra de tal modo que uses la humanidad tanto en tu persona como en la de cualquier otro, siempre como un fin y nunca meramente como un medio".

Kant aclara lo que piensa con algunos ejemplos. Uno es el de una persona que siente desapego por la vida y piensa si no será contrario al deber consigo mismo quitarse la vida. ¿Podría tornarse la máxima de esta acción en ley universal de la naturaleza?, ¿puede convertirse el principio del egoísmo en ley universal de la naturaleza? Según Kant rápido se ve que no: "que una naturaleza cuya ley fuese destruir la vida misma, por la misma sensación cuya determinación es atizar el fomento de la vida, sería contradictoria y no podría subsistir como naturaleza...". Otro ejemplo es si el estar apremiado de dinero me autoriza a pedirlo prestado, bajo promesa de que lo devolveré, aunque sé que no podré cumplir mi promesa. La máxima es, pues, aquí el principio del egoísmo o de la propia utilidad. Pues bien, según Kant no es lícito transformar esta máxima en ley universal, pues de inmediato se advierte que si alguien por estar apurado de dinero promete lo que sea por el deseo de obtener el préstamo, haría imposible la promesa misma y el fin que con ella puede obtenerse.

La ética kantiana ha sido criticada por diversas razones: por su formalismo y rigorismo que impiden cualquier desviación del deber; por su carácter poco atractivo para afrontar los problemas reales -por ejemplo, yo estaría siempre obligado a decir la verdad sean cuales fueren las circunstancias que me rodeen-; por la circunstancia de que incongruentemente abandona el plano de los principios para juzgar las consecuencias cuando Kant indica que el suicidio haría imposible la vida sobre la Tierra. 


\subsubsection{El utilitarismo}

En esta exposición sólo nos vamos a referir a los puntos de vista sostenidos por John Stuart Mill (1806-1873) en su libro El utilitarismo (1843). Siguiendo a Jeremy Bentham (1748-1832), Mill sostenía que el sumo bien moral es el principio de la utilidad o de la mayor felicidad. El principio de la utilidad sostiene que las acciones son correctas en la medida en que tienden a promover la felicidad, e incorrectas en cuanto tienden a producir lo contrario a la felicidad. Ésta es para el autor el placer, o sea la ausencia de dolor, siendo la infelicidad el dolor y la ausencia de placer. En esta medida el placer y la falta de sufrimiento son las únicas cosas deseables como fines. Todas las cosas deseables son deseables por el placer inherente a ellas mismas o como medios para procurar el placer y evitar el dolor.

Según Mill se ha objetado a esta doctrina colocar a los seres humanos al nivel de los cerdos, y se ha dicho que el epicureísmo tiene una visión degradada del ser humano; pero el problema está en verdad en sus acusadores: son ellos quienes suponen que el ser humano sólo puede experimentar un placer inferior, como sucede con el de los cerdos, sin advertir que hay además placeres superiores que son propios del ser humano y que corresponden no a los sentidos sino al intelecto, a los sentimientos y a la imaginación. En este sentido, los utilitaristas basan la superioridad de los placeres superiores en su mayor persistencia, seguridad y menor costo. Es decir que hay una diferencia entre los placeres por su diferente calidad: un placer superior es uno que emplea las capacidades humanas más elevadas. Por ello nadie en su sano juicio aceptaría convertirse en un animal inferior ante la promesa del más completo disfrute de los placeres de una bestia. Muchos dirán que esta negativa puede deberse al orgullo, al amor a la independencia o al amor al poder y a las emociones; pero Mill cree que se debe al sentido de la dignidad de los seres humanos, que guarda relación con nuestras facultades más elevadas y que constituye una parte esencial de la felicidad.

Por otro lado, el autor subraya que lo que aquí está en juego no es la mayor cantidad de placer para una persona sino para la mayoría de los seres humanos, es decir que el hedonismo del que aquí se trata no es egoista sino universalista. Conforme al principio de la mayor felicidad, el fin último de la vida sería una existencia libre del dolor -en la medida de lo posible- y tan 
rica como sea posible en goces -en cantidad y calidad-. El criterio y la regla de la calidad -al compararla con la cantidad- es la preferencia experimental por aquellos placeres que estén mejor dotados de los modos de comparación. Éstos constituyen los criterios de la acción humana y de la moralidad.

Mill manifiesta que se ha objetado que la felicidad no puede constituir el fin racional de la vida y de la acción humana, porque es inalcanzable y porque se podría prescindir de ella, ya que hay fines que algunas personas aprecian más como la autoinmolación y el sacrificio. A la primera objeción responde el autor manifestando que aun si la felicidad fuera inalcanzable, lo que el hombre persigue es -según el utilitarismo- no ser infeliz. A lo que se agrega que es un juego de palabras afirmar que el hombre no puede ser feliz. No puede serlo evidentemente si por felicidad se entiende una continua emoción altamente placentera. Pero puede lograrse si por ella comprendemos tan sólo algunos momentos brillantes de tal goce que preponderen sobre el sufrimiento. $\mathrm{Y}$ es que no se puede esperar más de la vida que lo que ella puede dar, y en este sentido lo que hay que buscar es una existencia que sepa combinar la tranquilidad con la emoción. Mucha tranquilidad ayuda a conformarse con el poco placer y mucha emoción a tolerar una considerable cantidad de dolor. Y no hay ninguna imposibilidad a priori para combinar sabiamente ambos. En cuanto a la segunda objeción el utilitarismo se niega, según Mill, a admitir que el sacrificio sea en sí mismo un bien.

Las objeciones contra el utilitarismo son muchas. De una parte, es casi imposible estimar todas las consecuencias que una acción pueda tener para "la mayoría de la gente". Por otra parte, choca que en el enjuiciamiento de las acciones morales se prescinda de las intenciones de sus autores y se tenga en cuenta sólo sus efectos o consecuencias -razón por la cual el utilitarismo es llamado también consecuencialismo-. Y, finalmente, si se adoptara el punto de vista utilitarista se estaría sacrificando en muchísimos casos a los integrantes de la minoría en nombre simplemente del peso o de la importancia de la mayoría: repugna en este sentido sostener que la muerte del docente y de los estudiantes de La Cantuta fueran la condición para la preservación del sistema legal peruano. 


\subsubsection{El neocontractualismo}

Denominamos neocontractualismo la postura según la cual las obligaciones morales derivan de un contrato que los seres humanos realizan hipotética o fácticamente. El contractualismo tuvo su auge en los siglos XVII y XVIII después de que Thomas Hobbes (1588-1679) enunciara su teoría del contrato social con respecto al origen de la sociedad, pero en nuestra época ha sido renovado con relación a las obligaciones políticas, morales y jurídicas. Aquí nos referiremos sólo a dos de las numerosas variedades del neocontractualismo contemporáneo: a las representadas por el contractualismo de estirpe kantiana de John Rawls y al de cepa hobbesiana de David Gauthier.

John Rawls (nacido en 1921 en Baltimore) publicó el año 1971 su obra A Theory of Justice (Una teoría de la justicia) y en 1993 Political Liberalism (Liberalismo politico). En la primera de estas obras Rawls sostiene, en contra del utilitarismo y en consonancia con Kant, que cada persona posee una inviolabilidad fundada en la justicia, que incluso el bienestar de la sociedad como un todo no puede atropellar. En este sentido, existe una clara prioridad de lo correcto o justo frente a lo bueno, que hace aconsejable elaborar una teoría de la justicia con respecto a toda la sociedad. Rawls entiende por sociedad una asociación más o menos autosuficiente de personas que reconocen ciertas reglas de conducta como obligatorias en sus relaciones y que en su mayoría actúan de acuerdo con ellas. Una sociedad está bien ordenada cuando está diseñada no sólo para promover el bien de sus miembros, sino cuando está efectivamente regulada por una concepción de la justicia.

La concepción de la justicia que el autor propone es la de la justicia como imparcialidad (fairness), en que, desde una posición original y provisto de un velo de ignorancia sobre su ubicación dentro de la sociedad, cada miembro de ésta escoge los principios de la justicia. Según Rawls estos principios son dos: uno, el principio según el cual cada persona habrá de tener un igual derecho al más amplio sistema de libertades básicas compatible con un sistema similar de libertades para todos; y un segundo principio, el de la diferencia, según el cual las desigualdades económicas y sociales habrán de articularse de modo que al mismo tiempo: a) redunden en el mayor beneficio de los menos favorecidos, y b) estén vinculadas con empleos y cargos que sean asequibles a todos, bajo condiciones de una justa igualdad de oportunidades. 
Estos dos principios son un caso especial de una concepción más general de la justicia según la cual todos los valores sociales deben estar igualmente distribuidos, a no ser que la distribución desigual redunde en provecho de todos. La desigualdad implica la situación opuesta.

Otra posición contractualista profundamente divergente de la anterior es la expuesta por David Gauthier en su libro Morals by Agreement (Moral por acuerdo, 1986). Según este autor los principios morales son de elección racional. De acuerdo con la visión usual de la elección, una persona racional elige aquello que le dará más expectativas de valor o utilidad. Pero en muchas ocasiones esto no es posible, como lo muestra el dilema del prisionero planteado por Gauthier -a dos personas encerradas en la cárcel por separado se les propone que confiesen, pero al precio de aplicar un castigo al otro: si una persona escoge confesar al otro le irá peor-. En consecuencia, la elección deberá hacérsele sobre la base del provecho mutuo, en lugar de buscarse la mayor utilidad individual. Una elección semejante piensa Gauthier que asegura el beneficio de los dos y que es imparcial y, además, que satisface los estándares de la moralidad. Es decir que en este caso se asegura la utilidad de cada uno siendo la elección además moral. Un ámbito semejante es el del mercado perfectamente competitivo, donde puede darse una maximización de las ganancias restringida para los participantes.

Pese a su éxito, las posiciones contractualistas también han sido objeto de profundas críticas. La de Gauthier, porque el egoísmo racional no parece muy moral que se diga, como habría sostenido Kant, y además porque en dicha concepción quedan totalmente desprotegidas las personas que o no aportan nada o aportan poco a la mesa del regateo. Y la de Rawls, porque tiene demasiados presupuestos: la preeminencia de la justicia sobre el bien, la posición original, el velo de la ignorancia, el equilibrio entre los distintos intereses, etc.

\section{4. Ética teórica y aplicada}

Denominamos ética teórica la consideración meramente especulativa de los problemas de la ética. El primero y más importante de ellos es el de la fundamentación o justificación de las normas morales, sobre todo desde que en la actualidad no se sigue aceptando las propuestas tradicionales y religiosas de fun- 
damentación -o mejor-: no son aceptadas por la generalidad de las personas o por la mayoría de la comunidad filosófica. Otros problemas importantes son los de los deberes morales, los del relativismo y falibilismo morales, los del libre arbitrio, los del rigorismo y latitudinismo morales, etc. En los últimos tiempos, un problema que se ha discutido mucho es el de la extensión de la comunidad moral: si ella está formada sólo por los seres humanos o también por los animales ${ }^{7}$, el medio ambiente, etc.

La ética aplicada es de su lado la reflexión ética que se proyecta a situaciones concretas. A ellas aplica las normas que antes fundamentó la ética teórica y, si fuera necesario, recaba la información imprescindible. Ricardo Maliandi expone esta referencia de la reflexión moral a la situación práctica con el siguiente esquema:

La relación de la ética aplicada con la normatividad puede representarse, a mi juicio, en el esquema siguiente, en el que la reflexión propia de la ética normativa y los aportes provenientes de la información científica (por lo general, de disciplinas diversas) convergen en la configuración de un tipo específico de "reflexión moral". Esta convergencia representa un primer paso -necesario pero insuficiente- de la "ética aplicada". La relación directa con la praxis se hace, en un segundo paso, desde la "reflexión moral" convenientemente ilustrada por la ética normativa y la ciencia.

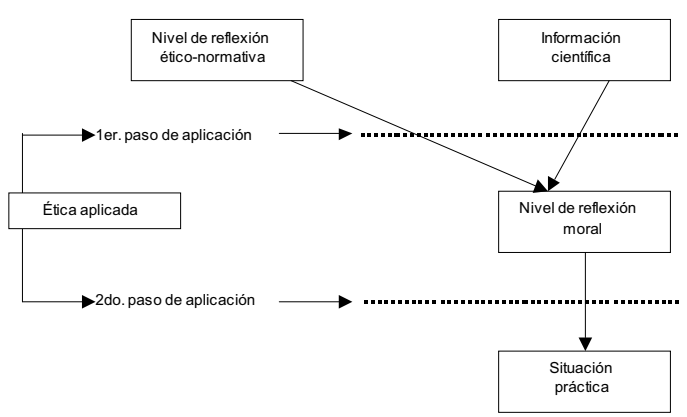

(De: Maliandi, Ricardo. Ética: conceptos y problemas. Buenos Aires: Biblos, 1991, pp. 68-69)

Existen diversos tipos de ética aplicada: bioética, ética deportiva, ética de la distinta actividad profesional, ética de las comunicaciones (sobre todo del periodismo), ética económica, etc. Uno de estos tipos es la ética de la empresa a la que a continuación nos referiremos.

7 Véase a este respecto el libro clásico de Peter Singer Liberación animal. Una ética nueva para nuestro trato hacia los animales [1975]. México: Torres, 1996. 
La ética aplicada no es, por lo tanto, una nueva clase de ética sino la proyección de la ética teórica a la consideración de casos prácticos, recabando previamente -si fuera necesario- la información científica imprescindible del caso. Aunque a veces la ética aplicada ha sido muy descuidada en muchos períodos de la historia, es de fundamental importancia porque, de otra manera, la reflexión ética no tendría ninguna aplicación y además porque, de otro modo, los casos éticos que se plantean en la vida cotidiana sólo recibirían una orientación de la ética cotidiana o de la religiosa que no pueden realizar una fundamentación teóricamente satisfactoria. Desde mediados del siglo XX la ética aplicada ha vuelto a merecer una gran atención debido a una serie de factores. Entre otros: el desarrollo de nuevas tecnologías médicas que afectan el final de la vida y su reproducción, las controversias políticas generadas por guerras como las de Vietnam y la de la antigua Yugoslavia, las discusiones generadas por los sufrimientos que se inflige a los animales a raíz del libro mencionado de Peter Singer y los escándalos suscitados en la vida económica pública y privada ${ }^{8}$.

\section{La ética de la empresa como un tipo de ética aplicada}

Podemos entender como ética de los negocios la aplicación insegura de principios éticos muy generales (por ejemplo el principio aristotélico de la virtud moral como el justo medio entre dos extremos, o el principio kantiano del "deber" o el principio de la "utilidad" como el mayor placer para la mayoría) a situaciones específicas del mundo de los negocios ${ }^{9}$. Decimos que se trata de una aplicación insegura básicamente por dos razones: porque algunas veces - no siempre sino en algunos casos muy contados- la aplicación de principios distintos lleva a resultados distintos ${ }^{10}$, y sobre todo porque, como sostiene Aristó-

8 Brenda Almond, V. "Introduction: Ethical Theory and Ethical Practice", en ídem, Introducing Applied Ethics. Londres: Blackwell, 1995, p. 5.

9 Solomon, V.R.C. "La ética de los negocios", en Peter Singer (ed.). Compendio de ética. Madrid: Alianza, 1995, pp. 483-497; esp. p. 483.

10 Por ejemplo, el robo de una vacuna muy costosa por un padre desesperado para salvar a su hijo enfermo sería sin duda desaprobada por la ética kantiana y seguramente justificada desde un punto de vista utilitarista. 
teles, en los asuntos que conciernen al comportamiento práctico no se puede alcanzar el mismo grado de rigor y exactitud que se logra en los asuntos teóricos como, por ejemplo, en el caso de las matemáticas o de la física ${ }^{11}$.

El mundo de los negocios puede ser estudiado en diferentes niveles. Uno de ellos es el nivel micro o sea de las relaciones cara a cara o relaciones interindividuales, donde no hallamos lo más peculiar de los negocios. Otro nivel es el macro, o sea el de las normas institucionales y culturales de comercio para toda una sociedad, nivel que por ser tan amplio tampoco nos permite captar lo característico del mundo de los negocios. El nivel propio de la ética de los negocios parece pues hallarse en el nivel molar: el de la empresa o corporación ${ }^{12}$ que es en el mundo occidental la instancia peculiar que impulsa los negocios-del Occidente esta institución se ha expandido a todas las otras culturas-.

La empresa puede ser caracterizada desde distintos puntos de vista. Desde el punto de vista jurídico es el ejercicio de una actividad económica organizada con el fin de actuar en el mundo de bienes y servicios y cuyos elementos integrantes son: la orientación socioeconómica, los medios materiales y humanos, la relación con terceros, la acción gerencial y la de los poseedores de acciones. Desde el punto de vista social es una organización jerárquica de seres humanos cuyo fin propio es la producción de bienes. Se trata de una forma social orientada a una meta económica: la realización del valor de lo útil con medios escasos. Desde el punto de vista económico es la organización voluntaria de individuos, integrada por una compleja multiplicidad de vínculos contractuales (donde están comprendidos personas, productos y procesos) con una función de asignar eficientemente recursos bajo la dirección y coordinación de la autoridad del empresario. Los managers son los auténticos rectores de la vida empresarial ${ }^{13}$.

Podemos pues ajustar nuestra definición sosteniendo que la ética de los negocios es la ética de la empresa, y ésta a su vez la

11 Véase, por ejemplo, Ética nicomaquea, I, 1, 1094 b, pp. 12-27.

12 Véase el artículo citado de Solomon, p. 489.

13 Lo anterior según Fernández Fernández, José Luis. Ética para empresarios y directivos. Madrid: ESIC, 1996, pp. 128-134. 
aplicación insegura de principios éticos generales a las situaciones éticas específicas que se plantean en la empresa. Podemos distinguir grosso modo entre el ambiente interno y externo de las organizaciones. El primero está constituido básicamente por los propietarios y accionistas de la compañía, por su Consejo de Administración, por los gerentes ${ }^{14}$, por los empleados en sus distintos niveles y los obreros. El segundo está integrado fundamentalmente por los clientes y el público en general, por los competidores, los proveedores, las organizaciones estatales, los grupos que representan intereses especiales y por el mismo entorno ecológico.

¿Cuáles son los problemas éticos específicos que se plantean dentro de la empresa? Son aquellos problemas que surgen con relación al cumplimiento de las obligaciones, ya sea en el ambiente interno o externo de la empresa. Algunas de las obligaciones existentes en el primero son las siguientes:

- De los accionistas frente a la empresa:

- No exigir de ella más beneficios de los que puede producir.

- No establecer una posición de privilegio sobre la base de la posesión de acciones que configuren una mayoría.

- Respetar los principios éticos que inspiran la actuación de la empresa.

- De la dirección de la empresa frente a los accionistas:

- Producir utilidades para los accionistas que justifiquen su inversión.

- Comunicar a los socios o accionistas con suficiente antelación los proyectos futuros y recabar su aprobación y sugerencias.

- No mantener "fondos secretos" para una finalidad ajena a los fines de la empresa.

- No facilitar información privilegiada que beneficie a unos accionistas en menoscabo de otros o de la propia empresa.

- De los gerentes de la empresa:

- Conseguir la máxima rentabilidad posible de la em-

14 Siendo los gerentes elementos importantísimos dentro de la empresa son sólo parte de ella. De allí que constituya un gran error reducir la denominación amplia y comprensiva de "ética de la empresa" a "ética de la gerencia". 
presa.

- Tratar humanamente a los trabajadores y no imponerles conductas humillantes, como el acoso sexual.

- Transmitir la información veraz que la empresa está obligada frente a sus propios accionistas, a los trabajadores y al Estado.

- No aprovechar de la situación de privilegio que se tiene para obtener ventajas económicas.

- Hacer cumplir las normas éticas de la empresa y establecer los mecanismos adecuados para que puedan ser cumplidas.

- De la empresa frente a los trabajadores (empleados y obreros):

- Pagar sueldos y salarios justos.

- Valorarlos en su capacidad y eficiencia.

- Garantizar los puestos de trabajo hasta donde lo permita la continuidad de la empresa.

- No hostilizar a los trabajadores.

- Velar porque los trabajadores cuenten con un seguro estatal o privado y por buenas condiciones de trabajo.

- Permitir y fomentar el desarrollo de los trabajadores.

- De los trabajadores (empleados y obreros) frente a la empresa:

- Realizar satisfactoriamente el trabajo por el que se percibe un sueldo o salario.

- Mantener frente a ella relaciones de lealtad.

- No recurrir a la huelga sino como último recurso y ejercitarla dentro de los límites y marcos legales.

- Cuidar y proteger los bienes de la empresa.

- No divulgar la información reservada de la empresa.

Algunas de las obligaciones existentes en el ambiente externo de la empresa son las siguientes:

- Con relación al público:

- Producir y distribuir bienes y servicios de calidad que satisfagan las necesidades y que garanticen la integridad, la seguridad y la salud de los consumidores, usuarios y clientes.

- Informar verazmente sobre los productos y servicios ofrecidos.

- Redactar los contratos de manera comprensible y sin 
subterfugios.

- Proceder al inmediato reemplazo de un producto o servicio que altere las condiciones ofrecidas.

- Garantizar el servicio posventa de los productos o servicios vendidos por sí mismos o por sus intermediarios.

- Con relación a los competidores:

- Respetarlos en su persona (individual o jurídica) y en sus productos y servicios.

- Competir con el objeto de brindar un producto o servicio de calidad.

- Usar lealmente la información confidencial de que se dispone.

- No contratar al personal calificado de los competidores con la finalidad de apropiarse de los conocimientos confidenciales de otras empresas.

- Con relación a los proveedores:

- Utilizar confidencialmente la información reservada de que se dispone sobre los proveedores.

- No imponerles condiciones que puedan conducir a un enfrentamiento de mala manera con los competidores.

- No actuar según la máxima: "te compro esto si no le vendes a otra firma”.

- Actuar con ellos justa y equitativamente -por ejemplo pagarles a tiempo-.

- Con relación al Estado y a las organizaciones políticas:

- Proporcionar verazmente la información que legal y moralmente le sea requerida.

- Cumplir con las obligaciones fiscales.

- Evitar la promoción o potenciación de actividades político-partidarias dentro de la firma.

- No hacer aportaciones económicas a organizaciones políticas o sindicales si ello no está permitido por ley o hacerlo -si está permitido-guardando las formas previstas.

- Con relación a la comunidad:

- Colaborar con ella en la satisfacción de las necesidades más urgentes de la colectividad según lo permita la situación de la empresa.

- Facilitar -dentro de los propios límites de la empresala participación de los trabajadores en actividades de tipo cívico, cultural o recreativo. 
- Con relación al medio ambiente:

- Respetar el equilibrio ecológico y urbanístico del entorno.

- Cultivar y extender las medidas de higiene.

- Utilizar tecnologías limpias.

- Colaborar en las campañas de protección medioambiental $^{15}$.

\section{Bibliografía citada}

Almond, B. (ed.)

Introducing Applied Ethics. Londres: Blackwell, 1995.

Brown, M.T.

La ética en la empresa. Estrategia para la toma de decisiones. Barcelona: Paidós, 1992.

Camps, V. (ed.)

Historia de la ética. 3 t. Barcelona: Crítica, 1988 ss.

Dupre, W.

Ethik in nichtchristlichen Kulturen. Stuttgart: Kohlhammer, 1984.

Fernández Fernández, José Luis

Ética para empresarios y directivos. Madrid: ESIC, 1996.

Guariglia, O.

La ética en Aristóteles o la moral de la virtud. Buenos Aires: Eudeba, 1997.

Iannone, A. Pablo (ed.)

Contemporary Moral Cotroversies in Business. Nueva York / Oxford: Oxford University Press, 1989.

Lipovetsky, G.

El crepúsculo del deber. La ética indolora de los nuevos tiempos democráticos. Barcelona: Anagrama, 1994.

15 Lo anterior, en gran parte, según la exposición de José Luis Fernández Fernández. Op. cit., pp. 214-219. 
López Gil, Martha y Lilia Delgado

De camino a una ética empresarial. Barcelona: Paidós, 1992.

Marzal, Manuel

La transformación religiosa peruana. Lima: PUC, 1983.

Pfeiffer, R.S. y R. Forsberg

Ethics on the Job. Cases and Strategies. Belomnt: Wadsworth, 1993.

Popkin, R. y A. Stroll

Philosophy made simple. Nueva York: Doubleday, 1993.

Ross, W.D.

Lo correcto y lo bueno. Salamanca: Sígueme, 1994.

Schmidt, E.

Ética y negocios para la América Latina. Lima: Universidad del Pacífico /OXY, 1995.

Singer, P. (ed.)

Compendio de ética. Madrid: Alianza, 1995.

Singer, $\mathrm{P}$.

Liberación animal. Una ética nueva para nuestro trato con los animales. México: Torres, 1996.

Smith, A.

Teoría de los sentimientos morales. Madrid: Alianza, 1997.

Thoreau, $\mathrm{H}$.

Walden. Del deber de la desobediencia civil. Barcelona: Parsifal, 1997.

Toulmin, S.E.

The Uses of Argument. Cambridge: Cambridge University Press, 1958.

Weiss, Joseph W.

Business Ethics. Belmont: Wadsworth, 1993. 